\title{
GONGOCOMPOSTO: SUBSTRATO ORGÂNICO PROVENIENTE DE RESÍDUOS DE PODA PARA PRODUÇÃO DE MUDAS DE ALFACE
}

\author{
Nathalia Oliveira Cruz Bugni ${ }^{1}$, Luiz Fernando de Sousa Antunes², José Guilherme Marinho Guerra ${ }^{3}$, \\ Maria Elizabeth Fernandes Correia ${ }^{4}$
}

\begin{abstract}
RESUMO - O substrato constitui-se em um dos fatores limitantes à produção de mudas, tornando-se importante o constante desenvolvimento de tecnologias que possibilitem produzir substratos a partir de materiais renováveis e de baixo custo. Este trabalho objetivou avaliar a eficiência dos substratos orgânicos obtidos pela gongocompostagem mediada pelo diplópode Trigoniulus corallinus, na produção de mudas de alface crespa. Os resíduos empregados na gongocompostagem foram os galhos finos e folhas de quatro espécies arbóreas: Terminalia catappa (Amendoeira), Licania tomentosa (Oiti), Senna siamea (Cassia), Albizia lebbeck (Albizia), os quais foram compostados por 120 dias. Os substratos gerados foram caracterizados quanto às suas propriedades físicas, físico-químicas e químicas. O delineamento experimental adotado foi o inteiramente casualizado, com 12 tratamentos e cinco repetições, dispostos em arranjo fatorial $6 \times 2$ (substratos com e sem adição de farelo de mamona). Aos 21 dias após a semeadura avaliou-se a massa fresca e seca da parte aérea, massa fresca e seca de raízes, o vigor da muda e estabilidade do torrão. A análise física e química dos gongocompostos revelou que as características se encontravam dentro de níveis adequados ao emprego como substratos. Os gongocompostos proporcionaram crescimento de parte aérea e de raízes semelhantes entre si, todavia, quando o farelo de mamona foi adicionado aos gongocompostos, as produções de parte aérea e de raízes foram otimizadas, sobretudo no substrato constituído de Licania tomentosa e Albizia lebbeck, que proporcionou a obtenção de mudas com vigor maior do que o substrato SIPA e menor apenas do que o substrato comercial avaliado.
\end{abstract}

Palavras chave: Agroecologia, gongolos, resíduos orgânicos, substrato orgânico.

\section{MILLICOMPOST: ORGANIC SUBSTRATE FROM PRUNING RESIDUES FOR THE PRODUCTION OF LETTUCE SEEDLINGS}

\begin{abstract}
The substrate is one of the factors limiting the production of seedlings, making constant the development of technologies that make it possible to produce substrates from renewable and low-cost materials. The objective of this work was to evaluate the efficiency of the organic substrates obtained by the millicompost mediated by the diplopods of the specie Trigoniulus corallinus in the production of crisp lettuce seedlings. The residues used in millicomposting were the thin branches and leaves of four tree species: Terminalia catappa (Amendoeira), Licania tomentosa (Oiti), Senna siamea (Cassia), Albizia lebbeck (Albizia), which were composted for 120 days. The substrates generated were characterized for their physical, physicochemical and chemical properties. The experimental design was completely randomized, with 12 treatments and five replications, arranged in $6 \times 2$ factorial arrangement (substrates with and without addition of Caster oil plant paste). At 21 days after sowing, fresh and dry mass of shoot, fresh and dry mass of roots, seed vigor and stability of the clod were evaluated. The physical and chemical analysis of the

\footnotetext{
${ }^{1}$ Engenheira Agrônoma | Mestra em Fitotecnia (PPGF-UFRRJ).

${ }^{2}$ Biólogo e Engenheiro Agrônomo | Mestre em Agronomia (CPGACS - UFRRJ) | Doutorando em Fitotecnia (PPGF-UFRRJ) | e-mail: fernando. ufrrj.agro@gmail.com.

${ }^{3}$ Engenheiro Agrônomo (UFRRJ) | Doutor em Agronomia (CPGACS - UFRRJ) | Pesquisador da Embrapa Agrobiologia.

${ }^{4}$ Bióloga (UFRJ) | Doutora em Agronomia (CPGACS - UFRRJ) | Pesquisadora da Embrapa Agrobiologia
} 
millicomposts revealed that the characteristics were within levels suitable for use as substrates. Millicomposts provided aerial and root growth similar to each other; however, when Caster oil plant paste was added to the millicomposts, aerial and root productions were optimized, especially in the substrate consisting of Licania tomentosa and Albizia lebbeck, which provided to obtain seedlings with greater vigor than the SIPA substrate and smaller only than the commercial substrate evaluated.,

Keywords: Agroecology, millipede, organic substrate, organic wastes.

\section{INTRODUÇÃO}

Considerando o cenário atual, onde cresce a cada dia o temor mediante à poluição ambiental e à limitação de recursos naturais, a melhor forma de destinação para resíduos sólidos orgânicos seria a decomposição através de processos biológicos controlados, reciclando os nutrientes presentes nos materiais e aproveitando o composto final para uso agrícola (Baratta Júnior, 2007).

A compostagem é um processo biológico de transformação da matéria orgânica presente nos resíduos em material humificado, que pode ser utilizado como adubo orgânico à agricultura, hortas e jardins, e até mesmo na recuperação de áreas degradadas (Campbell, 1999; Keener et al., 2000). Neste sentido, o uso de resíduos orgânicos como fornecedores de nutrientes e suporte para compor substratos pode representar uma alternativa para diminuir o custo de produção das mudas hortícolas (Silva Júnior et al., 2014).

Tendo em vista que um fator limitante para produção de mudas é a obtenção de substratos de qualidade a custos que viabilizem o negócio, torna-se importante o constante desenvolvimento de tecnologias que possibilitem produzir substratos a partir de materiais de baixo custo e fácil aquisição, como matéria orgânica residual (Steffen et al., 2010; Costa et al., 2015). Nesse contexto, o reaproveitamento dos resíduos das atividades urbanas, sobretudo, atividades de podas de espécies arbóreas, pode reduzir significativamente o custo de substratos para produção de mudas, em consequência da menor necessidade de se adquirir matérias-primas (Souza et al., 2013).

A gongocompostagem é uma biotecnologia que se baseia na atividade alimentar de diplópodes, conhecidos popularmente como gongolos ou piolhos-de-cobra (Antunes et al., 2018). Estes organismos fragmentam os resíduos vegetais, produzindo péletes fecais com diferentes características físico-químicas do material vegetal original, como por exemplo, a diminuição na relação carbono/ nitrogênio (Thakur et al., 2011; Karthigeyan \& Alagesan, 2011; Ramanathan \& Alagesan, 2012).
Antunes et al. (2016) ao utilizarem resíduos de aparas de grama, ramos e folhas de gliricídia e flemingia, sabugo de milho e casca de coco na produção de gongocomposto, verificaram que o gongolo da espécie Trigoniulus corallinus é capaz de decompor resíduos vegetais de origem agrícola e urbana, enriquecendo o composto gerado com cálcio, magnésio e fósforo, tornando o gongocomposto eficiente como substrato, permitindo a produção de mudas de alface com características que são semelhantes às produzidas usando substrato à base de vermicomposto de minhoca.

Diante do exposto, o presente trabalho objetivou avaliar a eficiência dos gongocompostos resultantes dos diferentes resíduos de podas arbóreas, os quais foram caracterizados quanto às suas propriedades físicas, físicoquímicas e químicas, sendo destinados à produção de mudas de alface em bandejas de poliestireno expandido.

\section{MATERIAL E MÉTODOS}

Os diplópodes da espécie Trigoniulus corallinus e o material vegetal proveniente das espécies arbóreas destinados à gongocompostagem foram coletados na área do Sistema Integrado de Produção Agroecológica, também conhecido como SIPA, criado em 1993, pertencente a Fazendinha Agroecológica Km 47. Quanto aos diplópodes, a coleta ocorreu manualmente, com as mãos devidamente protegidas com luvas de látex, em composteiras de resíduos agrícolas e áreas úmidas contendo resíduos vegetais acumulados.

O SIPA possui uma área de aproximadamente de 80 ha, está localizado no município de Seropédica - RJ, entre as coordenadas $22^{\circ} 46^{\prime} \mathrm{S}$ e $43^{\circ} 41^{\prime} \mathrm{W}$ e a $33 \mathrm{~m}$ de altitude em relação ao nível do mar (Dias, 2007). O clima é quente e úmido, classificado como Aw, com chuvas concentradas no período de novembro a março e precipitação anual média de 1213 mm (Cruz, 2005).

As espécies arbóreas utilizadas no experimento foram escolhidas tendo como base o número de árvores listadas em um levantamento realizado pela Comlurb 
(Companhia Municipal de Limpeza Urbana da Cidade do Rio de Janeiro) e pela Fundação Parques e Jardins, da Prefeitura do Rio de Janeiro, no ano de 2015, que foram as seguintes: Terminalia catappa (Amendoeira), Licania tomentosa (Oiti), Senna siamea (Cassia), Albizia lebbeck (Albizia) (Prefeitura da Cidade do Rio de Janeiro, 2015).

Para obtenção dos substratos a partir do processo de gongocompostagem, foram estabelecidas as seguintes proporções: $40 \%$ de aparas de Paspalum notatum (grama) + 30\% de dos resíduos de podas de cada uma das espécies arbóreas (folhas, folíolos e galhos finos, dispostos em galpão coberto para secagem natural antes de serem empregados à gongocompostagem), que foram triturados, sendo duas espécies leguminosas: Albizia lebbeck (Albízia) e Senna siamea (Cassia); e duas não leguminosas: Licania tomentosa (Benth) (Oiti) e Terminalia catappa (Amendoeira).

Após a secagem dos resíduos e preparo das misturas, estas foram adicionadas a 20 anéis de concreto com capacidade de $40 \mathrm{~L}$, nos quais foram adicionadas o volume de 0,3 L de gongolos em cada anel, equivalendo a uma população de aproximadamente 340 indivíduos adultos. O processo de gongocompostagem durou 120 dias, iniciado em maio de 2017 e finalizado em setembro de 2017. Durante o processo de gongocompostagem, a umidade dos resíduos contidos em cada anel foi mantida em torno dos 50-60\%, adicionando água com o auxílio de uma mangueira semanalmente ou quinzenalmente, conforme a necessidade. Cabe ressaltar que na gongocompostagem não há a necessidade do revolvimento periódico dos resíduos, ficando a cargo exclusivo dos gongolos todo o processamento dos resíduos. O delineamento experimental adotado nesta etapa experimental foi o inteiramente casualizado (DIC), com quatro tratamentos e cinco repetições.

Ao final dos 120 dias o material foi retirado, peneirado em malha de $2 \mathrm{~mm}$ e foram conduzidas as análises físicas e químicas. Para caracterizar os gongocompostos e o substrato SIPA quanto às suas características químicas, foram encaminhadas amostras de cada tratamento ao Laboratório de Química Agrícola da Embrapa Agrobiologia, para determinação dos teores de P, K, Ca e $\mathrm{Mg}$, de acordo com a metodologia descrita por Embrapa (2005). A determinação dos teores de N e C foi feita no analisador elementar (CHN), conhecido também como método de Dumas (Nelson \& Sommers, 1996). As análises de $\mathrm{pH}$ foram realizadas em solução de água destilada (5:1 $\mathrm{v} / \mathrm{v}$ ) e a condutividade elétrica foi determinada no mesmo extrato aquoso obtido para a medição do $\mathrm{pH}$, de acordo com o método descrito por MAPA (2007). Cabe ressaltar que foram feitas três repetições para todos os parâmetros avaliados.

As análises de densidade volumétrica, macro e microporosidade, porosidade total e capacidade de retenção de água dos substratos foram efetuadas seguindo a metodologia adaptada e contida na IN n ${ }^{\circ} 17$ do MAPA (2007). O material utilizado para as análises constituiu-se de 15 cilindros de alumínio (três repetições para cada um dos cinco tratamentos), com capacidade volumétrica de $100 \mathrm{~cm}^{3}$, nos quais foram adicionados os substratos até o seu volume total, e uma vedação em sua abertura inferior com folhas de TNT e elásticos. Os 15 cilindros foram saturados com água mantidos em drenagem, estando sua parte inferior em contato com folha de papel mata borrão (poros de diâmetro $\leq 0,0025 \mathrm{~cm}$ ou 2,5 mícrons).

Para avaliar a eficiência dos gongocompostos produzidos, optou-se pela produção de mudas de alface crespa cultivar Vera (Lactuca sativa). Os tratamentos empregados foram formados pelos quatro gongocompostos produzidos a seguir: S1 - AM+CA (40\% grama $+30 \%$ Amendoeira + 30\% Cassia); S2 - AM+AL (40\% grama + $30 \%$ Amendoeira + 30\% Albizia); S3 - OI+CA (40\% grama + 30\% Oiti + 30\% Cassia); S4 - OI+AL (40\% grama + 30\% Oiti + 30\% Albizia); S5 - SIPA (substrato que é produzido e utilizado rotineiramente na Fazendinha (SIPA), constituído de $83 \%$ de vermicomposto, $15 \%$ de fino de carvão vegetal e $2 \%$ de farelo de mamona (Oliveira et al., 2011) e S6 Biomix $^{\circledR}$ orgânico comercial.

Neste ensaio, foram adicionadas doses de $2 \%$ de farelo de mamona aos substratos formulados, visando o enriquecimento nutricional, sobretudo com referência ao nitrogênio, em forma prontamente assimilável pelas plantas. O farelo de mamona foi peneirado em malha de $2 \mathrm{~mm}$, eliminando-se, assim, as cascas secas e não desintegradas dos frutos da mamoneira.

Utilizaram-se bandejas de poliestireno expandido com 200 células para realizar a semeadura de Alface Crespa Vera. Foram adicionadas três sementes por célula e aos quatro dias após a semeadura foi efetuado o desbaste nas bandejas, mantendo então apenas uma muda por célula.

Aos 21 dias após a semeadura, foram retiradas, completamente ao acaso, seis mudas de alface por unidade experimental, das quais foram avaliadas os seguintes parâmetros: massa fresca da parte aérea (MFPA), massa seca da parte aérea (MSPA), massa fresca de raízes (MFR), massa seca das raízes (MSR), vigor da muda (VM) e estabilidade do torrão (ET). A massa seca da parte aérea e das raízes foram determinadas após a pesagem de suas 
respectivas massas frescas, sendo dispostas em sacos de papel e mantidas em estufa a $65^{\circ} \mathrm{C}$ por 72 horas e posteriormente pesadas.

O vigor das mudas (VM) foi determinado por uma adaptação metodológica de Franzin et al (2005), onde classifica-se com notas que vão de 1 a 4 , sendo nota $1=$ ótimo vigor, acima de 5 folhas, altura maior que $5 \mathrm{~cm}$; nota $2=$ vigor bom, 4 a 5 folhas, altura maior que $5 \mathrm{~cm}$ com amarelado não proeminente; nota $3=$ amarelecimento notório, 4 a 5 folhas, tamanho até $5 \mathrm{~cm}$, porém com deficiência nutricional bem destacada; nota $4=$ deficiência nutricional, problemas na altura, número de folhas reduzido.

A estabilidade do torrão (ET) é determinada por uma adaptação metodológica de Gruszynski (2002) e também é classificada de acordo com notas que vão de 1 a 4 , onde nota $1=50 \%$ ou mais do torrão fica retido no recipiente na retirada da muda; nota $2=30$ a $50 \%$ do torrão fica retido no recipiente na retirada da muda; nota $3=$ torrão destaca-se do recipiente, porém não permanece coeso; nota $4=$ o torrão é destacado completamente do recipiente e mais de $90 \%$ dele permanece coeso.
O delineamento experimental adotado foi o inteiramente casualizado, com 12 tratamentos e cinco repetições, dispostos em arranjo fatorial 6x2 (substratos com e sem adição de farelo de mamona). Para a análise estatística dos dados gerados, verificou-se a homogeneidade das variâncias dos erros pelo Teste de Bartlett e da normalidade pelo Teste de Shapiro-Wilk. Posteriormente, os dados foram submetidos à análise de variância, com a aplicação do teste Scott-Knott no nível de probabilidade de 5\%, com auxílio do programa estatístico SISVAR (Ferreira, 2008).

\section{RESULTADOS E DISCUSSÃO}

O valor de pH não diferiu entre os gongocompostos produzidos a partir dos resíduos de Amendoeira e Cassia (S1 - AM+CA), Amendoeira e Albizia (S2 - AM+AL), Oiti e Cassia (S3- OI+CA), Oiti e Albizia (S4 - OI+AL). Todavia, de acordo com a Tabela 1, os valores foram mais baixos do que o do substrato S5 - SIPA (elaborado a partir de mistura de vermicomposto de esterco bovino, carvão vegetal e farelo de mamona).

Tabela 1 - Valores de pH, condutividade elétrica, teores de macronutrientes e relação C/N dos substratos utilizados na produção de mudas de alface crespa

\begin{tabular}{cccccccccc}
\hline \multirow{2}{*}{ Substratos } & \multirow{2}{*}{$\mathrm{pH}$} & $\mathrm{CE}$ & Relação & \multicolumn{5}{c}{ Teor de macronutrientes $\left(\mathrm{g} \mathrm{kg}^{-1}\right)$} \\
\cline { 7 - 10 } & & $\left.(\mathrm{dS} \mathrm{m})^{-1}\right)$ & $\mathrm{C} / \mathrm{N}$ & $\mathrm{C}$ & $\mathrm{N}$ & $\mathrm{P}$ & $\mathrm{K}$ & $\mathrm{Ca}$ & $\mathrm{Mg}$ \\
\hline $\mathrm{S} 1$ - AM+CA & $7,33 \mathrm{~b}$ & $1,25 \mathrm{~b}$ & $19,09 \mathrm{a}$ & $408,64 \mathrm{c}$ & $21,41 \mathrm{a}$ & $1,81 \mathrm{~b}$ & $5,49 \mathrm{~b}$ & $24,65 \mathrm{~b}$ & $6,52 \mathrm{~b}$ \\
$\mathrm{~S} 2$ - AM+AL & $7,50 \mathrm{~b}$ & $1,22 \mathrm{~b}$ & $26,42 \mathrm{e}$ & $430,13 \mathrm{a}$ & $16,28 \mathrm{~b}$ & $1,48 \mathrm{~b}$ & $5,86 \mathrm{c}$ & $20,78 \mathrm{c}$ & $3,19 \mathrm{c}$ \\
S3 - OI+CA & $7,30 \mathrm{~b}$ & $1,22 \mathrm{~b}$ & $23,35 \mathrm{~d}$ & $417,11 \mathrm{~b}$ & $17,86 \mathrm{~b}$ & $1,74 \mathrm{~b}$ & $5,10 \mathrm{~b}$ & $21,74 \mathrm{c}$ & $2,84 \mathrm{c}$ \\
S4 - OI+AL & $7,43 \mathrm{~b}$ & $1,26 \mathrm{~b}$ & $22,78 \mathrm{c}$ & $422,28 \mathrm{~b}$ & $18,54 \mathrm{c}$ & $1,99 \mathrm{~b}$ & $5,17 \mathrm{c}$ & $27,15 \mathrm{a}$ & $2,89 \mathrm{c}$ \\
S5 - SIPA & $8,13 \mathrm{a}$ & $2,11 \mathrm{a}$ & $21,57 \mathrm{~b}$ & $326,73 \mathrm{~d}$ & $15,15 \mathrm{~d}$ & $5,25 \mathrm{a}$ & $6,27 \mathrm{a}$ & $14,95 \mathrm{~d}$ & $7,06 \mathrm{a}$ \\
\hline
\end{tabular}

Letras iguais na coluna não diferem entre si, pelo teste Scott-Knott a 5\% de probabilidade.

S1 - AM+CA (40\% grama + 30\% Amendoeira + 30\% Cassia); S2 - AM+AL (40\% grama + 30\% Amendoeira + 30\% Albizia); S3 - OI+CA (40\% grama + $30 \%$ Oiti $+30 \%$ Cassia); S4 - OI+AL ( $40 \%$ grama $+30 \%$ Oiti $+30 \%$ Albizia) e S5 - SIPA ( $83 \%$ de vermicomposto, $15 \%$ de fino de carvão vegetal e $2 \%$ de farelo de mamona).

Kratz (2011) considerou que valores ideais de $\mathrm{pH}$ devem estar situados entre 5,0 e 6,5, uma vez que nesta faixa, em teoria, há menor suscetibilidade das mudas à toxicidade provocada por sais e por elementos químicos, que limitam o pleno crescimento do sistema radicular, reduzindo a capacidade de absorção de nutrientes. Os valores de $\mathrm{pH}$ de todos os substratos (Tabela 1) foram superiores a faixa considerada ideal por Kratz (2011). O substrato SIPA, que divergiu estatisticamente dos demais, foi o mais alcalino, porém, esta característica físico-química não foi limitante à obtenção de mudas orgânicas vigorosas com padrão comercial.

A condutividade elétrica (CE) exprime a concentração de sais dos substratos. Araújo Neto et al. (2009) determinaram que os valores ideais de CE devem estar situados entre 1,0 e 2,0 dS m$~^{-1}$. Desta forma, pode-se observar na Tabela 1 que todos os gongocompostos avaliados apresentaram valores de CE dentro desta faixa, exceto o S5 - SIPA, cujo valor foi levemente maior do que o limite superior preconizado pelos autores supracitados, o que pode 
ser atribuído possivelmente à presença de farelo de mamona como um ingrediente usado na sua formulação, que apresenta rápida mineralização no substrato (Antunes, 2017).

Os teores de nutrientes variaram entre os substratos tanto em relação ao N, quanto ao P, K, Ca e Mg (Tabela 1). Com relação ao $N$, foi observada variação proporcional de até $42 \%$, quando se comparou o substrato S5 - SIPA e S1 - AM+CA. É relevante destacar o papel preponderante da disponibilidade de $\mathrm{N}$ no substrato para o crescimento de mudas, haja vista que afeta o desenvolvimento da parte aérea, o crescimento das raízes, a eficiência fotossintética, o processo de produção e translocação de fotoassimilados (Taíz \& Zieger 2004).

Em relação aos teores de $\mathrm{P}, \mathrm{K}$, Ca e de $\mathrm{Mg}$, as variações alcançaram, respectivamente, 255, 23, 82 e 49\% (Tabela 1), quando comparados os teores de nutrientes presentes no S5 - SIPA em relação ao gongocomposto S1 - AM + CA. Neste sentido, pode-se observar que os gongocompostos, oriundos da gongocompostagem com folhas e galhos finos de espécies arbóreas, apresentaram teores de P menores do que o substrato S5 - SIPA, cuja matriz é o vermicomposto de esterco bovino, além de ser enriquecido com farelo de mamona.

Em contrapartida, todos os substratos a base de gongocompostos apresentaram teores de Ca maiores do que o substrato S5 - SIPA. As menores variações proporcionais entre os substratos foram observadas para os teores de $\mathrm{K}$ (Tabela 1), sendo que os gongocompostos oriundos do processamento de folhas e galhos finos de cássia resultaram em valores semelhantes ao substrato S5 - SIPA. Valores dos teores de Mg semelhantes foram observados quando foram comparados os substratos S5 SIPA e o gongocomposto S1 AM+CA (Tabela 1). A diferença nos teores dos nutrientes $P$, K e Mg no substrato S5 - SIPA é atribuída ao esterco bovino e ao farelo de mamona, materiais ricos nestes nutrientes, corroborado por Antunes (2017), o qual também verificou superioridade nos valores de $\mathrm{N}, \mathrm{K}$ e $\mathrm{Mg}$ no substrato SIPA, destacando que o esterco bovino é a matéria-prima à vermicompostagem, mais rica em nutrientes.

Quanto às características físicas determinadas nos substratos (Tabela 2), observaram-se diferenças tanto entre o substrato S5 - SIPA, quanto entre os gongocompostos obtidos a partir da transformação de folhas e galhos finos derivados da combinação de espécies arbóreas mediada por indivíduos de diplópode Trigoniulus corallinus. Variações pequenas de densidade volumétrica (inferiores a 10\%), embora significativas $(\mathrm{p}<0,05)$, foram detectadas ao se comparar os gongocompostos entre si, porém, os valores foram muito menores do que o registrado para o substrato S5 - SIPA.

Tabela 2 - Percentuais de macroporosidade (MAC), microporosidade (MIC) e porosidade total (POT), capacidade de retenção de água a $10 \mathrm{~cm}$ de coluna d'água e densidade volumétrica (DV) dos substratos utilizados na produção de mudas de alface crespa

\begin{tabular}{|c|c|c|c|c|c|}
\hline \multirow{2}{*}{ Substratos } & MAC & MIC & POT & \multirow{2}{*}{$\begin{array}{c}\text { CRA } \\
\left(\mathrm{mL} 50 \mathrm{~cm}^{-3}\right)\end{array}$} & \multirow{2}{*}{$\begin{array}{c}\text { DV } \\
\left(\mathrm{kg} \mathrm{m}^{-3}\right)\end{array}$} \\
\hline & \multicolumn{3}{|c|}{-------------------- \% -------------------- } & & \\
\hline $\mathrm{S} 1-\mathrm{AM}+\mathrm{CA}$ & $28,55 \mathrm{c}$ & $53,01 \mathrm{~b}$ & $81,56 \mathrm{c}$ & $29,79 \mathrm{c}$ & $162,27 \mathrm{~d}$ \\
\hline $\mathrm{S} 2-\mathrm{AM}+\mathrm{AL}$ & $35,61 \mathrm{a}$ & 46,93 c & $82,54 \mathrm{c}$ & $23,73 \mathrm{~d}$ & $165,30 \mathrm{c}$ \\
\hline $\mathrm{S} 3$ - OI+CA & 29,46 b & $53,60 \mathrm{~b}$ & $83,06 \mathrm{~b}$ & $30,61 \mathrm{~b}$ & $162,70 \mathrm{~d}$ \\
\hline $\mathrm{S} 4-\mathrm{OI}+\mathrm{AL}$ & $30,09 \mathrm{~b}$ & 58,00 a & 88,09 a & 35,22 a & $179,30 \mathrm{~b}$ \\
\hline S5 - SIPA & $26,55 \mathrm{c}$ & 56,56 a & $83,11 \mathrm{~b}$ & $33,65 \mathrm{~b}$ & $371,20 \mathrm{a}$ \\
\hline
\end{tabular}

Letras iguais na coluna não diferem entre si, pelo teste Scott-Knott a 5\% de probabilidade.

S1 - AM+CA (40\% grama + 30\% Amendoeira + 30\% Cassia); S2 - AM+AL (40\% grama + 30\% Amendoeira + 30\% Albizia); S3 - OI+CA (40\% grama + $30 \%$ Oiti + 30\% Cassia); S4 - OI+AL (40\% grama + 30\% Oiti + 30\% Albizia) e S5 - SIPA ( $83 \%$ de vermicomposto, 15\% de fino de carvão vegetal e $2 \%$ de farelo de mamona).

Conhecer a densidade volumétrica dos substratos com vistas à produção de mudas é um fator de alta relevância, visto que se permite inferir sobre outras características físicas, bem como o ambiente do substrato influenciará a capacidade de retenção de água, o crescimento do sistema radicular e a acessibilidade à absorção de água e nutrientes pelas plantas (Fermino, 2003). 
Fermino (2003) ainda sugere que a faixa adequada de densidade volumétrica de substratos destinados à produção de mudas em bandejas se situa entre 100 e $300 \mathrm{~kg} \mathrm{~m}^{-3}$. Sendo assim, pode-se notar na Tabela 2, que os gongocompostos estão situados na faixa de valores supracitados. Em contrapartida, o substrato S5 - SIPA apresentou maior densidade que os gongocompostos e menor proporção de macroporos, o que pode ser entendido pela presença, por ocasião da formulação, de matériasprimas com menor diâmetro de partícula.

No que se refere à porosidade total, as variações entre os substratos apresentaram amplitude proporcional de apenas $2 \%$, detectada ao se comparar os gongocompostos oriundos da combinação de amendoeira e albízia (S2 $\mathrm{AM}+\mathrm{AL}$ ) e oiti e albízia (S4 - OI+AL), sendo determinante para este resultado o componente representado pelos microporos dos respectivos substratos (Tabela 2). De acordo com Gonçalves \& Poggiani (1996), a proporção adequada de microporos em substratos deve estar situada entre 45 e $55 \%$, o que foi verificado nos substratos avaliados, porém, deve-se assinalar que valores levemente superiores a esta faixa foram identificados nos substratos S5 - SIPA (57\%) e S4 - OI+AL (58\%).

Valores indicados como adequados para a porosidade total encontram-se na faixa de 75 a 85\% (Gonçalves \& Poggiani, 1996) e, neste sentido, todos os substratos avaliados, exceto o S4 - OI+AL, estavam nesta faixa. Poder-se-ia hipotetizar, que a mistura de folhas e galhos finos de oiti e albízia foi mais palatável aos gongolos, e por isso mais triturada. Corroborando com esta conjectura, pode-se notar que este tratamento foi o que apresentou maior densidade volumétrica (Tabela 2), o que vai ao encontro do possível maior grau de trituração, acarretando no menor tamanho de partícula ao final do processo de gongocompostagem. A porosidade total, assim como a densidade volumétrica, influencia diretamente nos processos de absorção de água e nutrientes pelas plantas (Kämpf, 2000).

Outra característica física importante inerente a qualquer substrato e, particularmente na produção de mudas de hortaliças em bandejas, é a capacidade de retenção de água. Tendo em vista que as células das bandejas comumente empregadas na produção de mudas de hortaliças são diminutas, um substrato que apresente baixa capacidade de retenção, ou que retenha água em excesso, não será adequado para este fim, visto que acarretará em problemas que impactarão no vigor e na qualidade das mudas, em decorrência, respectivamente, do déficit hídrico ou do excesso de retenção água no ambiente radicular.
Níveis adequados de retenção de água em substratos sugeridos por Gonçalves \& Poggiani (1996) encontram-se entre 20 e $30 \mathrm{ml} 50 \mathrm{~cm}^{-3}$. Nesta faixa pode-se notar que se encontram os gongocompostos S1 - AM+CA, S2 - AM+AL e s3 - OI+CA (Tabela 2). O substrato S4 - OI+AL e S5 - SIPA apresentaram valores maiores de capacidade de retenção de água, correspondendo, respectivamente, a 17 e $12 \%$ acima do limite sugerido pelos autores. Deve-se destacar a coerência entre os resultados de densidade volumétrica e capacidade de retenção de água, o que denota a relação próxima envolvendo estas características. Os substratos cujas densidades encontramse na faixa preconizada como ótima, são também aqueles que apresentam valores adequados de capacidade de retenção de água.

Na produção de mudas de alface, foram acrescidas doses de $2 \%$ de farelo de mamona aos gongocompostos assim como ao substrato comercial Biomix ${ }^{\circledR}$. Essa adição proporcionou alteração nos teores de macronutrientes presentes nos substratos (Tabela 3). Pode ser observado na Tabela 3 um incremento principal no teor de nitrogênio e fósforo nos substratos acrescidos de farelo de mamona, em comparação aos resultados mencionados na Tabela 1.

Esse incremento também foi observado por Oliveira (2011) ao comparar diferentes doses de farelo de mamona adicionadas em substratos orgânicos. A mesma autora, ao caracterizar a composição nutricional de farelo de mamona, registrou cerca de $4,4 \%$ a mais de nitrogênio e $3,16 \%$ a mais de fósforo do que em esterco bovino.

Os tratamentos que receberam aplicação de farelo de mamona obtiveram resultados superiores em relação aos tratamentos sem a adição, para os parâmetros de qualidade avaliados (Tabela 4), sendo esses: massa fresca de parte aérea e raiz; massa seca de parte aérea e raiz.

Nenhum substrato produzido sem farelo de mamona divergiu estatisticamente para massa fresca de parte aérea. Entre os tratamentos acrescidos de farelo de mamona, o substrato comercial S6 - Biomix ${ }^{\circledR}+\mathrm{FM}$ obteve valores superiores, seguido por $\mathrm{S} 4-\mathrm{OI}+\mathrm{AL}+\mathrm{FM}$ e demais gongocompostos (S1 - AM+CA+FM, S2 - AM+AL+FM e $\mathrm{S} 3$ - OI+CA+FM) e, posteriormente, S5 - SIPA. De todos os substratos produzidos, S1-AM+CA, S3 - OI+CA e S5 - SIPA não divergiram estatisticamente entre adição e ausência de farelo de mamona, para massa fresca de parte aérea.

O parâmetro massa seca de parte aérea seguiu um padrão semelhante ao de massa fresca, entre os substratos acrescidos de farelo de mamona. Não houve diferença estatística entre os tratamentos sem farelo; com relação 
aos tratamentos com farelo de mamona, os valores foram superiores para Biomix ${ }^{\circledR}+\mathrm{FM}$ e S4 - OI+AL+FM, seguidos pelos demais gongocompostos, e posteriormente pelo S5
- SIPA. No comparativo entre adição e ausência de farelo de mamona, não houve diferença estatística para S1 $\mathrm{AM}+\mathrm{CA}, \mathrm{S} 3$ - OI+CA e S5 - SIPA.

Tabela 3 - Teores de macronutrientes e relação C/N dos substratos com a adição de $2 \%$ de farelo de mamona (FM) utilizados na produção de mudas de alface crespa

\begin{tabular}{cccccccc}
\hline \multirow{2}{*}{ Substratos } & Relação & \multicolumn{5}{c}{ Teor de macronutrientes $\left(\mathrm{g} \mathrm{kg}^{-1}\right)$} \\
\cline { 3 - 7 } & $\mathrm{C} / \mathrm{N}$ & $\mathrm{C}$ & $\mathrm{N}$ & $\mathrm{P}$ & $\mathrm{K}$ & $\mathrm{Ca}$ & $\mathrm{Mg}$ \\
\hline S1 - AM+CA & 17,78 & 426,10 & 23,97 & 3,07 & 4,78 & 26,94 & 4,36 \\
S2 - AM+AL & 17,91 & 421,26 & 23,52 & 2,94 & 4,01 & 21,76 & 3,00 \\
S3 - OI+CA & 16,43 & 412,48 & 25,11 & 3,20 & 3,28 & 21,07 & 3,45 \\
S4 - OI+AL & 16,67 & 422,70 & 25,36 & 3,12 & 3,65 & 22,55 & 3,67 \\
S5 - SIPA & 21,58 & 326,74 & 15,14 & 4,46 & 2,93 & 12,41 & 6,04 \\
S6 - BIOM+FM & 32,54 & 293,45 & 9,02 & 1,81 & 1,67 & 7,33 & 2,96 \\
\hline
\end{tabular}

S1 - AM+CA (40\% grama + 30\% Amendoeira + 30\% Cassia); S2 - AM+AL (40\% grama + 30\% Amendoeira + 30\% Albizia); S3 - OI+CA (40\% grama + $30 \%$ Oiti + 30\% Cassia); S4 - OI+AL (40\% grama + 30\% Oiti + 30\% Albizia); S5 - SIPA ( $83 \%$ de vermicomposto, $15 \%$ de fino de carvão vegetal e $2 \%$ de farelo de mamona) e S6 - Biomix ${ }^{\circledR}$ orgânico enriquecido com farelo de mamona (FM).

Tabela 4 - Valores médios de massa fresca e seca de parte aérea e raízes, das mudas de alface produzidas utilizando os diferentes substratos sem adição e com a adição de farelo de mamona (FM)

\begin{tabular}{|c|c|c|c|c|c|c|c|c|}
\hline \multirow[t]{2}{*}{ Substratos } & \multicolumn{2}{|c|}{$\begin{array}{c}\text { MFPA } \\
\left.\text { (g planta }^{-1}\right)\end{array}$} & \multicolumn{2}{|c|}{$\begin{array}{c}\text { MSPA } \\
\left.\text { (g planta }^{-1}\right)\end{array}$} & \multicolumn{2}{|c|}{$\begin{array}{c}\text { MFR } \\
\left.\text { (g planta }^{-1}\right)\end{array}$} & \multicolumn{2}{|c|}{$\begin{array}{c}\text { MSR } \\
\left.\text { (g planta }^{-1}\right)\end{array}$} \\
\hline & Sem FM & Com FM & Sem FM & Com FM & Sem FM & Com FM & Sem FM & Com FM \\
\hline S1 - AM+CA & 0,48 Аа & 0,68 Ba & 0,036 Aa & 0,052 Ba & 0,16 Аа & 0,22 Аа & 0,012 Aa & 0,017 Aa \\
\hline $\mathrm{S} 2-\mathrm{AM}+\mathrm{AL}$ & $0,32 \mathrm{Ab}$ & 0,89 Ва & $0,026 \mathrm{Ab}$ & 0,041 Ba & $0,12 \mathrm{Ab}$ & 0,29 Аа & 0,009 Ab & 0,019 Aa \\
\hline $\mathrm{S} 3-\mathrm{OI}+\mathrm{CA}$ & 0,68 Аа & 0,74 Ba & 0,045 Аa & 0,051 Ba & 0,17 Аа & 0,30 Aa & 0,011 Ab & 0,021 Aa \\
\hline $\mathrm{S} 4-\mathrm{OI}+\mathrm{AL}$ & $0,38 \mathrm{Ab}$ & 1,07 Aa & 0,029 Ab & 0,069 Аа & $0,15 \mathrm{Ab}$ & 0,32 Аa & 0,009 Ab & 0,021 Aa \\
\hline S5 - SIPA & $0,42 \mathrm{Aa}$ & 0,60 Ba & 0,043 Аа & 0,042 Ba & 0,18 Аа & 0,28 Аа & 0,013 Аа & 0,016 Аа \\
\hline S6 - Biomix ${ }^{\circledR}$ & 0,63 Ab & 1,20 Аа & 0,050 Ab & 0,089 Аа & $0,21 \mathrm{Aa}$ & 0,33 Аа & 0,015 Ab & $0,024 \mathrm{Aa}$ \\
\hline CV \% & \multicolumn{2}{|c|}{17} & \multicolumn{2}{|c|}{23} & \multicolumn{2}{|c|}{26} & \multicolumn{2}{|c|}{28} \\
\hline
\end{tabular}

Médias seguidas de letras distintas, maiúsculas na coluna e minúsculas na linha, diferem entre si pelos testes $\mathrm{F}$ e Scott-Knott a 5\% de probabilidade, respectivamente.

S1 - AM+CA (40\% grama + 30\% Amendoeira + 30\% Cassia); S2 - AM+AL (40\% grama + 30\% Amendoeira + 30\% Albizia); S3 - OI+CA (40\% grama + $30 \%$ Oiti + 30\% Cassia); S4 - OI+AL (40\% grama + 30\% Oiti + 30\% Albizia); S5 - SIPA ( $83 \%$ de vermicomposto, $15 \%$ de fino de carvão vegetal e $2 \%$ de farelo de mamona) e S6 - Biomix ${ }^{\circledR}$ orgânico.

Em relação aos tratamentos sem adição de farelo de mamona, resultados semelhantes foram obtidos por Antunes (2017), de obtenção de massa fresca e seca de alface, utilizando gongocompostos de 125 dias, tal qual no presente trabalho. Os resultados dos tratamentos com adição de farelo de mamona, também foram semelhantes ou superiores aos resultados obtidos pelo autor supracitado, desta vez, quando o mesmo utilizou substratos produzidos com 180 dias. Levando em consideração o elevado teor de $\mathrm{N}$ presente em farelo de mamona, cerca de 5,86\% (mais de 4 vezes superior a esterco bovino) (Oliveira, 2011) e os resultados semelhantes aos de Antunes (2017), é possível afirmar que um maior tempo disponível para degradação dos resíduos de podas de espécies arbóreas, poderia contribuir para aumentar o nível de $\mathrm{N}$ assimilável para as mudas. 
Com relação a massa fresca de raiz, dentre os tratamentos sem essa adição, não houve diferença significativa. Entre os tratamentos com adição do farelo de mamona, também não ocorreram diferenças estatísticas. Ainda para o mesmo parâmetro, comparando os substratos com e sem a adição do farelo de mamona, apenas os substratos S2 - AM+AL e S4 - OI+AL diferiram estatisticamente.

Não houve diferença estatística entre os tratamentos sem a adição de farelo de mamona para massa seca de raiz e entre os substratos acrescidos de farelo de mamona. Ao se comparar estatisticamente cada tratamento com e sem a adição de farelo de mamona, apenas os substratos S1 - AM+CA e S5 - SIPA não apresentaram diferença estatística.

Não houve diferença estatística para o parâmetro vigor de mudas entre os tratamentos sem adição de farelo de mamona, assim como entre os tratamentos com a adição do farelo de mamona (Tabela 5).

Tabela 5 - Valores médios das notas de vigor de muda e estabilidade do torrão, atribuídas às mudas de alface produzidas utilizando os diferentes substratos sem adição e com a adição de farelo de mamona

\begin{tabular}{ccccc}
\hline \multirow{2}{*}{ Substratos } & \multicolumn{2}{c}{ Vigor de muda } & \multicolumn{2}{c}{ Estabilidade do torrão } \\
\cline { 2 - 5 } & Sem farelo & Com farelo & Sem farelo & Com farelo \\
\hline S1 - AM+CA & $1,96 \mathrm{Aa}$ & $1,20 \mathrm{Aa}$ & $3,30 \mathrm{Aa}$ & $3,63 \mathrm{Aa}$ \\
$\mathrm{S} 2$ - AM+AL & $2,30 \mathrm{Ab}$ & $1,16 \mathrm{Aa}$ & $3,03 \mathrm{Aa}$ & $3,63 \mathrm{Aa}$ \\
$\mathrm{S} 3$ - OI+CA & $1,46 \mathrm{Aa}$ & $1,00 \mathrm{Aa}$ & $3,60 \mathrm{Aa}$ & $3,76 \mathrm{Aa}$ \\
S4 - OI+AL & $1,70 \mathrm{Aa}$ & $1,00 \mathrm{Aa}$ & $3,16 \mathrm{Ab}$ & $3,96 \mathrm{Aa}$ \\
S5 - SIPA & $2,00 \mathrm{Aa}$ & $1,43 \mathrm{Aa}$ & $2,90 \mathrm{Ab}$ & 3,53 \\
S6 - Biomix & $1,40 \mathrm{Aa}$ & $1,00 \mathrm{Aa}$ & $3,76 \mathrm{Aa}$ & $3,96 \mathrm{Aa}$ \\
CV $\%$ & & & & 8 \\
\hline
\end{tabular}

Médias seguidas de letras distintas, minúsculas na linha e maiúsculas na coluna, diferem entre si pelos testes F e Tukey, a $5 \%$ de probabilidade, respectivamente $\mathrm{S} 1$ - AM+CA (40\% grama + 30\% Amendoeira + 30\% Cassia); S2 - AM+AL (40\% grama + 30\% Amendoeira + 30\% Albizia); S3 - OI+CA (40\% grama + $30 \%$ Oiti $+30 \%$ Cassia); S4 - OI+AL (40\% grama + 30\% Oiti + 30\% Albizia); S5 - SIPA ( $83 \%$ de vermicomposto, $15 \%$ de fino de carvão vegetal e $2 \%$ de farelo de mamona) e S6 - Biomix ${ }^{\circledR}$ orgânico.

O substrato S2 - AM+AL apresentou diferença estatística entre os valores sem/com a adição do farelo de mamona, apesar de o tratamento S5 - SIPA sem adição de farelo de mamona também ter proporcionado a obtenção de mudas com o vigor inferior aos demais substratos. Uma vez que as notas atribuídas para caracterizar o vigor de mudas estão entre 1, quando ótimo e 4, quando péssimo, todos os tratamentos acrescidos de farelo de mamona foram capazes de produzir bandejas com mudas de alface de excelente vigor.

O parâmetro estabilidade do torrão, ao contrário do anterior, é caracterizado por notas decrescentes, onde nota 4 sugere um torrão retirado com coesão e nota 1 quando mais de $50 \%$ do torrão se desfaz na retirada da muda. Sendo assim, todos os tratamentos acrescidos de farelo de mamona foram capazes de gerar torrões completamente destacáveis das bandejas, com até $90 \%$ do torrão coeso; apenas os substratos S4 - OI+AL e S5 - SIPA, com e sem adição do farelo de mamona, apresentaram diferenças estatísticas, embora todos os tratamentos sem adição do farelo de mamona tenham apresentados notas inferiores aos tratamentos que receberam a adição de $2 \%$ de farelo de mamona.

As notas de vigor de muda e estabilidade do torrão dos gongocompostos produzidos com resíduos de poda enriquecidos com $2 \%$ de farelo de mamona ( $\mathrm{S} 1, \mathrm{~S} 2$, S3 e S4) corroboram com os dados encontrados por Antunes et al. (2018), que buscaram avaliar o desempenho agronômico da alface cultivar Vera sob sistema de produção orgânico, de acordo com a qualidade das mudas produzidas a partir de diferentes gongocompostos, onde registraram para o gongocomposto de 180 dias notas de vigor de muda de 1,23 e 3,03 para a estabilidade do torrão.

Antunes et al. (2018) destacam a importância da produção de mudas com vigor e qualidade, características que influenciam diretamente no desempenho final das 
plantas, tanto do ponto de vista nutricional como produtivo, pois as mudas transplantadas com vigor e qualidade comprometidos demorarão mais tempo para restabelecer-se, comprometendo seu ciclo produtivo. Da mesma forma, uma muda que é retirada da bandeja e tem seu sistema radicular exposto, apresentará problemas no campo com perdas consideráveis de umidade decorrentes do estresse gerado, tanto pela ruptura de suas raízes ou exposição, aumentando as falhas no estande e a necessidade de replantio.

\section{CONCLUSÕES}

Gongocompostos obtidos a partir da mistura de resíduos de espécies arbóreas leguminosas e não leguminosas mostram-se adequados como substratos para produção de mudas orgânicas de alface. A adição de farelo de mamona aos gongocompostos empregados como substratos permite otimizar a produção de mudas orgânicas de alface.

\section{LITERATURA CITADA}

RAMANATHAN, B.; ALAGESAN, P. Evaluation of millicompost versus vermicompost. Current Science, v.103, n.2, p.140-143, jul. 2012.

ANTUNES, L. F. DE S.; SCORIZA, R. N.; FRANÇA, E. M.; SILVA, D. G. DA; CORREIA, M. E. F.; LEAL, M. A. DEA.; ROUWS, J. R. C. Desempenho agronômico da alface crespa a partir de mudas produzidas com gongocomposto. Revista Brasileira de Agropecuária Sustentável (RBAS), v.8, n.3, p.57-65, 2018.

ANTUNES, L.F.S. Produção de Gongocompostos e sua Utilização como Substrato para Mudas de Alface. 2017. 73p. Dissertação de Mestrado em Agronomia - Ciência do Solo. Universidade Federal Rural do Rio de Janeiro, Seropédica- RJ, 2017.

ANTUNES, L. F. S.; SCORIZA, F. N.; SILVA, D. G.; FERNANDES, M. E. C. Production and efficiency of organic compost generated by millipede activity. Ciência Rural, Santa Maria-RS, v.46, n.5, p.815-819, 2016.

ARAÚJO NETO, S.E.; AZEVEDO, J.M.A.; GALVÃO, R.O.; OLIVEIRA, E.B.L.; FERREIRA, R.L.F. Produção de muda orgânica de pimentão com diferentes substratos. Ciência Rural, v.39, n.5, 2009.

BARATTA JUNIOR, A.P. Utilização do composto de resíduos da poda da arborização urbana em substratos para produção de mudas. Dissertação de mestrado. Seropédica: UFRRJ, 2007. 53p. Dissertação (Mestrado em
Ciências Ambientais e Florestais). Instituto de Florestas, Universidade Federal Rural do Rio de Janeiro, Seropédica, RJ, 2007.

CAMPBELL, S. Manual de compostagem para hortas e jardins: como aproveitar bem o lixo orgânico doméstico. São Paulo. Nobel, 1999, 149p.

COSTA, E.; SANTO, T. L. E.; SILVA, A. P.; SILVA, L. E.; OLIVEIRA, L. C.; BENETT, C. G. S.; BENETT, K. S. S. Ambientes e substratos na formação de mudas e produção de frutos de cultivares de tomate cereja. Horticultura Brasileira, v. 33, n. 1, p. 110-118, 2015.

CRUZ, F. A. DA. Instalação e calibração de lisímetro de pesagem e determinação da evapotranspiração de referência para a região de Seropédica-RJ. 2005. 65p., (Dissertação, mestrado em Fitotecnia), Universidade Federal Rural do Rio de Janeiro, Seropédica-RJ, 2005.

DIAS, J. E. Monitoramento do uso da terra e dos níveis de nutrientes no solo Sistema Integrado de Produção Agroecológica utilizando geoprocessamento. Tese (Doutorado em Fitotecnia). Departamento de Fitotecnia, Instituto de Agronomia, Universidade Federal Rural do Rio de Janeiro, 2007. 111 p.

EMBRAPA. Manual de laboratórios: solo, água, nutrição, animal e alimentos. São Carlos: Embrapa Pecuária Sudeste, 2005. 334p.

FERMINO, M.H. Métodos de análise para caracterização física de substratos para plantas. 2003. 81f. Tese (Doutorado em Fitotecnia) - Faculdade de Agronomia, Universidade Federal do Rio Grande do Sul, Porto Alegre.

FERREIRA, D. F. SISVAR: um programa para análises e ensino de estatística. Revista Symposium (Lavras), v. 6, p. 36-41, 2008.

FRANZIN, S.M.; MENEZES, N.L.; GARCIA, D.C.; SANTOS, O.S. Efeito da qualidade das sementes sobre a formação de mudas de alface. Horticultura Brasileira, Brasília, v.23, n.2, p.193-197, 2005.

GONÇALVES, J. L. M.; POGGIANI, F. Substrato para produção de mudas florestais. In: SOLO-SUELO - CONGRESSO LATINO AMERICANO DE CIENNCIA DO SOLO, 13, 1996. Águas de Lindóia-SP. Relação de trabalhos. Águas de Lindóia: SLCS/SBCS/ESALQ/USP/ CEA-ESALQ/USP/SBM, 1996. 1 CD ROM.

GRUSZYNSKI, C. Resíduo agro-industrial "casca de tungue" como componente de substrato para plantas. Porto Alegre: UFRGS. 2002. p. 41. (Tese mestrado).

KÄMPF, AN. Seleção de materiais para uso como substrato. In: ENCONTRO NACIONAL SOBRE SUBSTRATOS PARA 
PLANTAS, 1. Substratos para plantas: a base da produção vegetal em recipientes. Porto Alegre: Genesis, p. 139-145, 2000.

KARTHIGEYAN, M.; ALAGESAN, P. Millipede composting: a novel method for organic waste recycling. Recent Research in Science and Technology, v.3, n.9, p.6267, 2011.

KEENER, H. M.; ELWELL, D. L., MONNIN, M. J. Procedures and equations for sizing of structures and windrows for composting animal mortalities. Applied Engineering in Agriculture, v. 6, p. 681-692, 2000.

KRATZ, D. Substratos renováveis na produção de mudas de Eucalyptus benthamii Maiden et Cambage e Mimosa scabrella Benth [dissertação]. Curitiba: Universidade Federal do Paraná; 2011.

MINISTÉRIO DA AGRICULTURA, PECUÁRIA E ABASTECIMENTO (MAPA). Secretaria de Defesa Agropecuária (SDA). Instrução Normativa SDA No 17 de 21 de maio de 2007. Métodos Analíticos Oficiais para Análise de Substratos e Condicionadores de Solos. Diário Oficial da União, Brasília, DF, 24 de maio 2007. Seção 1, p.8.

NELSON, D.W.; SOMMERS, L.E. Total carbon, organic carbon, and organic matter. In: SPARKS, D.L. et al. (Eds.). Methods of Soil Analysis. Madison: SSSA and ASA. 1996. 983 p.

OLIVEIRA, E.A.G. Desenvolvimento de substratos orgânicos, com base na vermicompostagem, para produção de mudas de hortaliças em cultivo protegido. Dissertação de mestrado. Seropédica: UFRRJ, 2011. 78 p.

PREFEITURA DA CIDADE DO RIO DE JANEIRO. Plano Diretor de Arborização Urbana da cidade do Rio de Janeiro, 2015. Disponível em: <http://www.rio.rj.gov. br/dlstatic/10112/5560381/4146113/PDAUtotal5.pdf $>$ Acesso em: 06 Nov. 2016.

SILVA JÚNIOR, J. V.; CAVALCANTE, M.Z.; BRITO, S.L.S.; AVELINO, R.C.; CAVALCANTE， I.H.L. Aproveitamento de materiais alternativos na produção de mudas de tomateiro sob adubação foliar. Revista Ciência Agronômica, v. 45, n. 3, p. 528-536, 2014.

SOUZA, E. G. F.; BARROS JÚNIOR, A. P.; SILVEIRA, L. M.; SANTOS, M. G.; SILVA, E. F. Emergência e desenvolvimento de mudas de tomate IPA 6 em substratos. Contendo esterco ovino. Revista Ceres, v. 60, n. 6, p. 902907. 2013.

STEFFEN, G. P. K.; ANTONIOLLI, Z. I.; STEFFEN, R. B.; MACHADO, R. G. Casca de arroz e esterco bovino como substratos para a multiplicação de minhocas e produção de mudas de tomate e alface. Acta Zoológica Mexicana, n. 2 (número especial), p. 333-343, 2010.

TAÍZ, L.; ZIEGER, E. Fisiologia vegetal. 3ed., Porto Alegre: Artemed, 2004, p.719.

THAKUR, P.C. et al. Comparative study of characteristics of biocompost produced by millipedes and earthworms. Advances in Applied Science Research, v.2, n.3, p.94-98, 2011.

Recebido para publicação em 05/03/2019 e aprovado em 20/08/2019. 